\title{
Life Skills Education for Enhancement of Learners' Wellness in Eswatini: A Case of High School Learners in Shiselweni Region
}

\author{
Zanele Precious Simelane Racheal Mafumbate \\ University of Eswatini, Department of Educational Foundations and Management, Faculty of Education
}

\begin{abstract}
The researchers sought to explore how Life Skills Education enhances learners' wellbeing. The study adopted a qualitative research approach using a multiple case study design. The study used an integrative lens and was guided by the Wellness theory by Hettler (1996) and Ubuntu theory. The target population were Life Skills Education teachers and high school learners in the Shiselweni region. A purposive sample of three high schools was selected. Data were collected using semi-structured interview guide and focus group discussion guide. Interviews were conducted with a total of nine learners whereas focus group discussions were carried out with twenty Life Skills Education teachers. Data was analysed using thematic analysis. Findings revealed several dimensions in which Life Skills Education enhances learners which include: socially, emotionally, intellectually, and occupationally. It was recommended that 1) the Ministry of Education and Training should consider training teachers who will specialise in teaching Life Skills Education, 2) Life Skills Education be considered a compulsory component in all pre-service teacher preparatory programmes, and that 3) mechanisms be put in place to ensure appropriate identification of teachers who will teach Life Skills Education.
\end{abstract}

Keywords: Life skills, Life Skills Education, wellness, enhancement

DOI: $10.7176 / \mathrm{JRDM} / 59-06$

Publication date:September $30^{\text {th }} 2019$

\section{Introduction}

Life Skills preparation for adulthood is a crucial, yet overlooked concept in education. In schools across the United States for example, young adults graduate from high schools with limited knowledge regarding how to navigate through the expectations of the real world (Cassidy, 2018). In our highly competitive and rapidly changing world, it is increasingly critical that learners enter into adulthood with skills for lasting success. Education, though constantly evolving, has one primary goal: to prepare learners to be independent and responsible members of society (Meier \& Naude, 2017). WHO (2011) observes that young people are not sufficiently equipped with Life Skills Education to help them deal with increased demand and stress they experience. Parental influence in moulding moral and social values and the traditional school curriculum are seemingly becoming increasingly incapable of equipping young people with the skills needed to face real life (Wairimu, 2015). To make the life of adolescents valuable, and to convert them to individuals with high potential, there is need for the educational system to be reformed, giving due importance to Life Skills Education.

KICD (2009) defines life skills as psychosocial competencies which enable an individual to develop adaptive and positive behaviour so as to deal effectively with challenges and demands of everyday life. Life Skills Education aims at providing a deeper understanding of life skills especially in the case of adolescents (Chaudhary, Mehta, \& Kapadia, 2012). The subject is aimed at guiding and preparing learners for life and its possibilities, including equipping them for a meaningful and successful living in a rapidly transforming society (Meier \& Naude, 2017). Through Life Skills Education, learners are exposed to a range of knowledge, skills and values that strengthen their physical, social, personal, emotional, and cognitive development. Moreover, the programme provides individuals with strategies to make healthy choices that contribute to a meaningful life (Parvarthy \& Renjith, 2015). The major set of life skills include: decision-making, creative thinking, critical thinking, effective communication, interpersonal relationship skills, self-awareness, empathy, coping with emotions, and coping with stress (WHO, 2011).

In most countries in Latin America and the Caribbean, schools are in struggle to expand appropriate learning and life skills programmes (UNESCO, 2012). Countries are increasingly signalling the importance of equipping young people with knowledge and skills to make responsible choices in their lives. Uganda, for instance, produced a booklet: Life Skills Education Resource Booklet: Helping Young Ugandans to be strong and make choices for a bright and safe future (UNESCO, 2015). This was a deliberate attempt to encourage all people who worked with children and adolescents to adapt a Life Skills Education approach to their work. In Eswatini too, policy makers and youth-serving professionals are grappling with how best to address the wideranging needs of young people (WHO, 2012). The underlying assumption is that empowering young people to make informed decisions about their own lives and helping them develop critical thinking skills will result in better lives. In 2011, the Ministry of Education and Training through the director's office launched the Guidance and Counselling panel to develop a syllabus that will be age-specific in its approach, and will handle Guidance and Counselling, Health Promotion including HIV/AIDS, and Life Skills Education in all secondary/high 
schools (Mtshali, 2011). Young people hold the promise of our future and they are our demographic force. However, there are many challenges facing the youth today as a result of the fast changing world (UNESCO, 2015). Changing times have challenged society to find means to protect and empower young people to live and become happy and healthy adults. Life Skills Education was conceptualized as one of the means to improve the well-being of the youth by empowering them to deal with the many challenges of life. At the world conference on education for all, Jomtien 1990, the international society raised concern about the relevance of education, particularly, on the need to focus on appropriate Life Skills for all learners around the world.

\section{Statement of the problem}

Ngcamphalala (2015) in the Eswatini State of the Youth Report posits that adolescents and youth in Eswatini do not have adequate information and accessibility to services which will enable them to make informed decisions about their lives. The report further reveals a variety of challenges that today's Swati youth are facing which will require a comprehensive, coordinated, and multi-sectorial response from the government, development partners, and other relevant stakeholders (Ngcamphalala, 2009). These challenges include: violence, adolescence pregnancy, high school dropout rate, HIV/AIDS prevalence, and drug and substance abuse. The vulnerabilities that the inadequate knowledge creates for young people are especially critical to address, hence the study was conducted to explore ways in which Life Skills Education enhances high school learners' wellness in Shiselweni Region of Eswatini.

\section{Theoretical framework}

The study was guided by the Hettler's Wellness theory (1996). This theory postulates that there are six dimensions of wellness, namely: academic, social, spiritual, physical, occupational, and emotional wellness. Hettler (1984) explains intellectual wellness to constitute 'stimulating the mind for stimulation sake; keeping one engaged in meaningful, informed conversation on an ongoing basis'. Intellectual wellness requires curiosity and a strong desire to learn, solving problems, thinking independently, creatively and critically (Adebayo, 2013). This dimension meshes together the state of one's knowledge, skills and creativity for problem solving and teaching (Adebayo, 2013). According to Hettler (1984), intellectual wellness represents a commitment to lifelong learning, an effort to share knowledge with others, and development of skills and abilities to achieve a more satisfying life (Long, 2012). This dimension of wellness theory highlights the important role of supporting students through academic counselling and according to Baba (2014) academic / educational guidance involves continuous sessions that include study skills, workshops, group academic advising sessions, social gathering with academic staff, assertiveness training, sexuality programmes that can include concerns about dating, sexually transmitted diseases, especially HIV/AIDS education, alcohol awareness, among others. Also, students' academic success programme, and student's welfare rights advocacy component are a part of the educational guidance (Baba, 2014). Also, the counsellor, through classroom individual and group counselling, can assist students in applying effective study skills, setting goals, learning effectively, and gaining test-taking skills (Thamarasseri, 2014). Counsellors also may focus on note taking, time management, memory techniques, relaxation techniques, overcoming test anxiety, and developing listening skills subsequently (Thamarasseri, 2014).

The link between teachers' understanding of life skills education and ways in which they impart the schools to learners enhances school learners' wellness. (Tatar \& Myers, 2010; Myers \& Sweeney, 2007), teachers' strengths and teaching strategy differ and that these strengths are unique and differ in terms of how they influence the enhancement process to individual learners on their wellness needs. Each teacher adopts different methods for satisfaction and promotion of same/similar fundamental wellness needs. The wellness theory served as a lens through which the study explored ways in which Life Skills Education enhances high school learners' wellness in Shiselweni Region of Eswatini.

\section{Review of related literature}

In a constantly changing environment, having life skills is an essential part of being able to meet the challenges of everyday life (Confederation of British Industry, 2011). To cope with the increasing pace and change of modern life, learners need new life skills such as the ability to deal with stress and frustration. The Confederation of British Industry (2011) further postulates that in everyday life, the development of life skills helps learners find new ways of thinking and problem-solving, and to recognise the impact of their actions. Sharing the same sentiments is Monyangi (2010) who concluded that life skills are relevant especially in helping learners exercise self-control. This was confirmed by $90 \%$ of the respondents in the study who indicated that Life Skills Education changes the pupils' behaviour and is very useful to schools. Okech (2015) concurs with Monyangi (2010) in that $92 \%$ of the respondent learners agreed that Life Skills Education had assisted them in developing various psychosocial competencies which enabled them to deal with challenges of modern living. Moreover, these learners admitted that the programme had assisted them in understanding themselves. Furthermore, Okech (2015) 
established that Life Skills Education is vital as it helps in providing young people with options for positive behaviour and encourages the development of self- esteem, confidence, and informed decision-making.

Similarly, Parvarthy and Renjith (2015) in India established several benefits of Life Skills Education which include: improvement of self-esteem among learners, increasing happiness, quality of life and emotion regulation, decrease mental disorder symptoms especially anxiety, depression and stress among learners, and also help them achieve psychological, social and mental well-being. Khera and Khosla (2012) on the other hand, concluded that there is a positive correlation between core-affective life skills and self-concept of adolescents. The study revealed that adolescents who possess these essential skills are better confident in all aspects.

Aparna and Raakhee (2011) also in India, concur with Khera and Khosla (2012) and noted that imparting life skills in children and adolescents brings valuable benefits which include: promotion of self-esteem, peace education, and self-confidence. Aparna and Raakhee (2011) further posit that Life Skills Education helps in the prevention of antisocial activities and behaviour, promotion of general well-being, and enables individuals to translate knowledge, attitudes and values into actual abilities. The study further revealed that Life Skills Education improves academic performance of individuals. Moreover, Life Skills Education enables adolescents to behave in healthy ways, given the desire to do so and given the scope and opportunity to do so (TACADE, 2013).

Kitimo (2014) also supports the idea of Life Skills Education in schools. She observed that the introduction of Life Skills Education in schools is a worthwhile investment considering that the potential gains are far reaching. According to Kitimo (2014) apart from helping to mold an individual child, there are benefits for the school as an institution because Life Skills Education improves teacher-learner relationship, classroom behaviour and academic performance. Moreover, Kitimo (2014) observed that school attendance is also improved and fewer causes of student unrest are reported in schools where Life Skills Education is properly taught. Meanwhile, Adhiambo (2013) concurs with Kitimo (2014) in that in the study by Adhiambo (2013) the majority of learners showed that Life Skills Education enhances their social skills. Perhaps they felt that socialisation was more important in their lives due to adolescence experiences among them. Twenty per cent of the learners indicated that Life Skills Education helps them to cope up with stress as they underwent their secondary education. The stress might be due to personal growth experiences which are characterised by ego. Other students (15\%) reported that Life Skills Education aids them gain effective decision-making and coping with life difficulties. This is mainly because some learners were experiencing difficulties such as lack of enough money for school fees and other basic needs like learning materials.

Additionally, Sridevi (2015) emphasized the importance of directing the education of a child towards development of childhood personality, talents, and mental health and physique to full potential. Sridevi (2015) further established that Life Skills Education makes it relatively easier to instil values and influence young people at this formative stage to develop responsible and safe behaviour in future life. Learners are also at a stage of experimentation. At this stage, Life Skills Education enables them to make informed and responsible choices about their life styles. Moreover, correct information and values imparted to one group of young people passes easily to other young people.

Sharing the same view are Srikala and Kishore (2010) who concluded that the main aim of life skills intervention is to make adolescent girls perform better in all walks of life by acquiring psychosocial competencies, finding proper solutions to day-to-day problems, creating positive attitude, coping with different situations in life, and improving ability. These findings are supported by Ravindran and Parthasarathy (2012) who reported that Life Skills Education as an adolescent intervention strategy is promising to be the preventative and promotive functions of social work. The study by Ravindran and Parthasarathy (2012) further revealed that the intervention on life skills such as problem-solving, creative thinking, critical thinking, coping with stress and empathy helped adolescent girls to take positive actions to protect themselves, in solving problems, coping with stress and to promote positive social relationships.

Furthermore, Mpande (2013) established that Life Skills Education was worth teaching in basic schools and pointed out that knowledge, skills and values were being acquired through the programme.

\section{Research Methodology}

The study adopted a qualitative research approach using a multiple case study design to explore various ways in which Life Skills Education enhances learners' wellness in high schools in the Shiselweni Region of Eswatini. The multiple case study design was appropriate for this study as it allows multiple methods of data collection to be used to investigate a research problem (Choongwa, 2018). The target population for the study was fifty (50) Life Skills Education teachers and four hundred (400) high school learners in the Shiselweni Region. These consisted of Life Skills Education teachers and learners from the five high schools where the Life Skills Education programme was piloted in the Shiselweni Region. The teachers from these schools were targeted since they facilitate the teaching and learning process of the Life Skills Education syllabus in their respective schools and are therefore, knowledgeable on issues of life skills. Learners were targeted because they are beneficiaries of 
the Life Skills Education curriculum. Three high schools where the Life Skills Education programme was piloted were selected using purposive sampling.

Data was collected using semi-structured interview guide and focus group discussion guide. Interviews were conducted with three learners per school whereas focus group discussions were carried out with seven Life Skills Education teachers per school. Trustworthiness was ensured by paying attention to 1) credibility, 2) transferability, 3) confirmability, and 4) dependability. Data was analysed using thematic analysis by Braun and Clarke (2006), also known as thematic networks techniques by Choongwa (2018). This is an interpretive process, where data is systematically searched to identify patterns within data in order to provide illuminating description of the phenomenon (Joana \& Jill, 2011).

\section{Findings and Discussions}

The study revealed that Life Skills Education is a worthwhile programme for the youth as it helps them understand themselves, and empowers them with many capabilities to face challenging situations. From participants' responses, it transpired that Life Skills Education enhances learners' wellness in various aspects such as: socially, emotionally, intellectually, and occupationally. The following are themes that emerged during the in-depth interviews, and focus group discussions regarding Life Skills Education enhancing learners' wellness

\subsection{Theme 1: Social Enhancement}

Findings revealed that Life Skills Education has a positive influence on learners' behaviour. The study revealed that through Life Skills Education, learners are able to distinguish between good and bad or right and wrong. Findings revealed that participants associated Life Skills Education with development of character among learners. Moreover, the subject helps learners to make right choices in life. For instance, they are able to go about choosing good friends who will not mislead them in life. Additionally, Life Skills Education enables learners to have a better understanding of themselves and the teenage stage. From the findings, it emerged that the subject helps teach them how to handle or manage the teenage stage, making things easier even for their teachers. Participants also pointed out that Life Skills Education teaches them to exercise self-control. They further indicated that the subject helps them understand one another and eliminates misconceptions about each other such as the feeling of being looked down upon by others.

The following are participants' voices with regard to the above statements: "Life Skills Education enables us to make right choices in life, for instance, we are now able to choose right friends. The subject makes us to be focused and avoid friends or things that add no value to our future lour lives. It helps build a positive attitude in us so that we become the best that we can be" (Learner 3, a female student from Case C).

"Through Life Skills Education, even learners who are orphaned or less privileged are able to get information and guidance from teachers on how to live an upright life. The subject also helps teach learners on how to go about choosing right friends" (Learner 2, a female student from Case A).

"Life Skills Education has helped us in choice of friends. As learners, we are now able to identify good friends who will not deter us from achieving our goals. Life Skills Education also enables us to take responsibility or be accountable for what we do rather than blaming others. It enables learners to make proper decisions in life" (Learner 1, a female student from Case A).

Findings revealed that Life Skills Education helps equip learners with skills that enable them to deal effectively with the demands and challenges of everyday life. Through these skills, learners are able to cope in the midst of challenges. Participants further concurred that the subject helps inculcate in learners skills that help them to live in harmony with others and at the same time resist peer-pressure and other unhealthy practices. These findings are consistent with Okech (2015) who observed that Life Skills Education had assisted learners in developing various psychosocial competencies that help them to deal with challenges of modern living and helps them understand themselves.

Sharing similar sentiments was Parvarthy and Renjith (2015) who identified several benefits of Life Skills Education to learners that include quality of life and emotion regulation, improvement of self-esteem, increasing happiness, and also helping them achieve psychological, social and mental wellbeing.

\subsection{Theme 2: Emotional Enhancement}

Findings pointed out that Life Skills Education has not only equipped learners to make informed decisions but has also taught them how to handle their emotions. Most of the learner participants emphasised that the subject has helped them to manage their affairs, to cope with stress, and to handle emotions. One learner from Case B, for instance, pointed out that Life Skills Education has taught her to manage her anger. The study also established that Life Skills Education is effective in promoting self-confidence and self-esteem among young people. The learners learn to accept themselves and who they are.

The following is an example of a quote from one participant in an in-depth interview: "Life Skills 
Education has helped me a lot. I am now able to deal with my anger. I used to overreact when angry, but now I am able to control or handle my emotions" (Learner 1, a female student from Case C).

These findings in this study are consistent with findings by Sridevi (2015) who emphasised the importance of directing the education of a child towards development of childhood personality and talents to full potential. Sridevi (2015) also posited that the participatory learning approach used in Life Skills Education is integral for life skills development because it means that what was discussed, understood, practiced, and applied by the learner and not just what the teacher delivered. The findings therefore, vividly noted that Life Skills Education is worth teaching and learning despite the many challenges met in its implementation.

\subsection{Theme 3: Intellectually}

The study also established that Life Skills Education is effective in making learners to be focused and organised. From the responses, it transpired that through Life Skills Education, learners get to understand and avoid practices that are detrimental to a young person's life. They develop a positive attitude towards their academic work, their teachers and life in general. This in turn, leads to improved academic performance. In support, one participant from Case $\mathrm{C}$ reported that generally, their learners lack the culture for learning, but Life Skills Education has helped improve or build a positive attitude on them.

Below are some quotes from participants in the focus group discussions and in-depth interviews, supporting the above views: "Life Skills Education encourages positive living among learners. It makes them to focus on their future and take education seriously. Through Life Skills Education, for instance, we are now able to take our academic work seriously without being pushed. We have learned to value our education. We now understand the purpose of being at school. This has made classroom management easier for both teachers and prefects" (Learner 2, a male student from Case B).

"Life Skills Education helps improve learners' academic performance. As learners, we tend to be focused on our learning and avoid bad practices. This even reduces the rate of disciplinary cases in our school" (Learner 3, a female student in Case C).

\subsection{Theme 4: Occupationally}

Findings of the study pointed out that Life Skills Education is worth teaching and learning because it promotes and encourages entrepreneurial skills among learners. Participants noted that Life Skills Education empowers learners holistically as it equips them with both social and entrepreneurial skills, and is thus practical. The programme fosters development of skills such as decision-making, creative thinking, problem-solving, interpersonal relationships, to name a few. Findings revealed that Life Skills Education has equipped learners not only with social but also entrepreneurial skills. Learners have learned to apply what they learn in the classroom to their own lives.

In support, the following were voices of participants from the focus group discussions and in-depth interviews: "The programme has helped us in identifying our potential or capabilities. We are now able to start our own businesses. For example, I have started a pie business using the skills I have acquired in the Life Skills Education lessons" (Learner 1, a female student from Case C).

Additionally, findings indicated that Life Skills Education does not only promote development of cognitive and social skills but also equips learners with entrepreneurial skills. The programme empowers learners holistically and is therefore practical. Through Life Skills Education, learners are able to apply in real life situations what they have learned in the classroom. In support of these findings, Mpande (2013) opined that Life Skills Education was worth teaching and learning because it promoted and encouraged entrepreneurial skills or productivity among learners.

The study established that Life Skills Education enables learners to identify their potentials, boost their selfesteem, and makes them develop a positive attitude towards their schoolwork. These findings are consistent with Srikala and Kishore (2010) who observed positive changes in classroom behaviour and interaction among learners in the Life Skills Education programme compared to those who were not in the programme. Learners in the programme were significantly better adjusted to the school and teachers compared to those not in the programme.

\section{Conclusion}

Based on the findings above, one may safely conclude that Life Skills Education has several benefits to learners and thus a worthwhile programme for the youth. Both learner and teacher participants concurred that Life Skills Education is a worthwhile programme as it helps empower learners with quite a number of capabilities. Findings revealed that the subject enhances social, emotional, intelligent, and occupational wellness in learners.

\section{Recommendations}

In light of the above findings, the following recommendations are made to policy makers and relevant 
stakeholders:

a) The Ministry of Education and Training should consider training teachers who will specialise in teaching Life Skills Education. Such training is crucial for teachers as Life Skills Education is taught differently from other subjects.

b) Life Skills Education may be considered a compulsory component in all pre-service teacher preparatory programmes

c) Mechanisms may be put in place to ensure appropriate identification of teachers who will teach Life Skills Education.

\section{References}

Adhiambo, L.P. (2013). Implementation of Life Skills Education in Secondary Schools. Unpublished Thesis. Kenyatta University.

Aparna, N. \& Raakhee. A.S. (2011). Life Skill Education for Adolescents: its Relevance and Importance. GESJ: Education Science and Psychology 2(19) 65-69.

Braun, V. \& Clarke, V. (2006). Using thematic analysis in psychology. Qualitative Research in Psychology, 1(3) $77-101$.

Cassidy, K. (2018). Preparation for Adulthood: A Teacher Inquiry Study for Facilitating Life Skills in Secondary Education in the United States. Journal of Educational Issues. 4(1) 33-45.

Chaudhary, S.,Mehta, B. \& Kapadia, S. (2012). A Life Skills Intervention Program for Adolescents: Contextual Approach. Retrieved from http://i08.cgpublisher.com/proposals.html.

Choongwa, G. H. (2018). Fundamentals of Applied Research Methodology: A Complete Guide for Scholars and Researchers in Social Sciences ( $1^{\text {st }}$ ed.). Mbabane: Swaziland. Webster Print.

Confederation of British Industry (2011). Importance of Life Skills. Mcmillan: London.

Hettler, B. (1976). Wellness promotion on university campus. Family and community health. Journal of Health Promotion and Maintenance, 3(1): 77-95.

Joanna, S. \& Jill, F. (2011). Qualitative data analysis: the framework approach. Nurse Researcher, 18(2) 52-62.

Khera, S. \& Khosla, S. (2012). A Study of Core Life Skills of Adolescents in Relation to their Self Concept. International Journal of Science and Interdisciplinary Research, 11(1)1-11.

KICD (2009). Primary Life Skills Education Teacher's Handbook. Nairobi: Kenya Institute of Education Kenya Institute of Curriculum Development.

Kitimo, M. (2014). Factors Influencing the Implementation of Life Skills Education in Secondary schools in Kinango District. Unpublished Thesis. Kenyatta University.

Meier, C. \& Naude, M. (2017). Teaching Life Skills in the Foundation Phase. Van Schaik: Pretoria.

Monyangi, N.L. (2010). Teachers' Perceptions Towards Implementation of Life Skills Curriculum in Public Primary Schools in Nairobi West District, Kenya. Unpublished Thesis. University of Nairobi.

Mpande, A. (2013). The extent to which knowledge, skills, attitudes and values are being acquired through life Skills Education: A case of selected basic schools of Kafue District. Unpublished Thesis. University of Zambia.

Mtshali, S.M. (2011). Secondary/High School Guidance and Counseling Teaching Syllabus. Mbabane: Swaziland.

Ngcamphalala, D. C. (2009). National Youth Policy. Mbabane: Swaziland.

Ngcamphalala, D.C. (2015). State of the Youth Report. Mbabane: Swaziland.

Okech, D.O. (2015). Implications of Life Skills Education on Character Development in Children: A Case of Hill School. Unpublished Thesis. Africa Nazarene University, Nairobi.

Parvarthy, V. \& Renjith, R. (2015). Impact of Life Skills Education on Adolescents in

Rural Schools. International journal of Advanced Research: 3(2) 2320-5407.

Ravindran, D. \& Parthasarathy, R. (2012). Participants' evaluation of a Life Skills Education programme among high school students. Conference of ISPSW on Emerging Trends in Professional Social Work, 5-7, January, 2012, Department of Psychiatric Social Work, Bangalore.

Sridevi, Y. (2015). Life Skills Education in India. International Journal of Multidisciplinary Advanced Research Trends ISSN: (2) 2349-7908.

Srikala, B. \& Kishore, K.V. (2010). Empowering adolescents with life skills education in schools- School mental health programme: Does it work? Indian Journal of Psychiatry, 52(4) 344-349.

Thamarasseri, I. (2014). Meta-narrative on guidance and counselling in schools. Central University of Kashmir. India.

TACADE (2013). Skills for the Primary School Child: Promoting the Protection of Children. UK: Salford.

UNESCO (2012). Youth and Skills: Putting education to work. EFA Global Monitoring Report.

UNESCO (2015). Framework for Action for Education 2030. UNESCO, Paris. 
UNICEF (2012). Report on the national Life-skills Education forum. Unpublished:Nairobi.

Wairimu, K. H. (2015). Factors Influencing Implementation of Life Skills Education In Primary Schools In Starehe Sub-County. Nairobi, Kenya.

WHO (2011). Preventing violence by developing life skills in children and adolescents. Viewed 30 April 2013.

WHO (2012). Partners in Life Skills Education. United Nations Inter-Agency Meeting held at WHO Heard quarters in Geneva, Switzerland. 